\title{
Bandas armadas en los campos de la Corona de Castilla (siglos XIII-XV)*
}

\section{Armed bands in the countryside of the Kingdom of Castile}

\author{
José María Sánchez Benito \\ Universidad Autónoma de Madrid
}

Fecha de recepción: 13.01 .16

Fecha de aceptación: 18.03.2016

\section{RESUMEN}

No es difícil constatar que la presencia de bandas armadas en los campos castellanos fue bastante frecuente a lo largo de los siglos XIII-XV. Profundizando un poco más se observa -también con relativa facilidad- que los objetivos que tenían no quedaban solamente en el robo o el secuestro. Por el contrario, tales bandas, aunque diversas, se insertaban perfectamente en la conflictividad política de la época y en el entramado de la sociedad feudal. Tal es el objeto de estudio de este artículo, en cuyas páginas proponemos indagar en la variedad que presentan estos grupos para poner de manifiesto sus características, objetivos y causas. De este modo comprobaremos que la violencia depredadora que practicaban estaba a menudo orientada por los poderes de la época, a cuyas pautas e intereses servían. A tal fin comenzaré tratando acerca de golfines y almogávares a fines del siglo XIII, cuya peripecia nos permitirá una primera reflexión acerca de los factores que rodean la práctica del bandidaje. Después avanzaremos cronológicamente hacia el siglo XV, siempre atentos a las agrupaciones que, adecuadamente organizadas, tenían capacidad para llevar a cabo delitos graves en despoblado y al contexto en el cual surgían.

PALABRAS CLAVE: bandas armadas, Castilla, golfines, nobleza, violencia

\section{ABSTRACT}

It is not difficult to show that the presence of armed bands in the Castilian countryside was quite frequent throughout the XIII-XV centuries. If we go more deeply, we can observe, with relative ease, that their purpose was not only thefts and kidnapping. On the contrary, although varied in their nature, they were fully involved in the political tensions of that period as well as in the framework of the feudal society. This is the study objective of this article. Consequently, we propose to inquire into

* Este artículo se ha realizado en el marco del proyecto Ciudad y nobleza en la Castilla de la Baja Edad Media: la (re)construcción de un marco de relaciones competitivo, financiado por el Ministerio de Economía y Competitividad, referencia HAR2013-42787-P. 
the wide range of these groups with the aim of making their characteristics, objectives and causes clear. In this way we will confirm that their violence was often guided by the powers of the time and that they served their rules and interests. To this end, we will start by looking at golfines and almogávares of the end of the XIII century. Their behavior will allow us to make an initial reflection about the factors that surround the practice of banditry. Then we will continue chronologically to the $\mathrm{XV}$ century, always focused on properly organized groupings that had the capacity to carry out serious offenses in deserted areas and the context in which they arose.

KEY WORDS: armed bands, Castilian Kingdom, golfines, nobility, violence

\section{INTRODUCCIÓN}

Cuando cualquier persona, aunque sea un estudioso experto, se aproxima al tema del presente artículo, casi sin querer vienen a la mente las imágenes tópicas del bandolero, teñidas de romanticismo y con tantas connotaciones literarias. Entre dichas imágenes suelen destacar dos especialmente, por una parte el carácter popular de los protagonistas y, por otra, la bondad de su comportamiento, en perfecta sintonía con el entorno rural en cuyo seno cobra vida la actividad que desarrollan. De este modo, Robin Hood $^{1}$ es el ejemplo característico y los bosques medievales el mejor escenario. Pero, claro, al analizar los datos existentes -seguro que no tantos como desearía el investigador-inmediatamente se observa que no hubo en el Medievo castellano nada parecido, de manera que lo primero que debemos hacer es alejarnos con presteza de las mencionadas imágenes tópicas -incluyendo alguna propuesta procedente de medios académicos- y todo lo que, de una u otra manera, comportan. Frente a tópicos y estereotipos, lo cierto es que la acción de bandas armadas en los campos castellanos fue en el período que vamos a estudiar bastante frecuente y, sin la menor duda, sus objetivos no se quedaban solamente en el robo o el secuestro. Antes al contrario, tales bandas, practicando una violencia siempre depredadora, se insertaban perfectamente en la conflictividad política de la época y en las redes que de manera descendente penetraban de arriba abajo la estructura social.

Efectivamente, el objeto de estudio de este trabajo son las diversas bandas armadas que actuaron en Castilla entre los siglos XIII y XV contando con jerarquía y organización. Tales bandas cometieron delitos a veces espectaculares y siempre muy graves desde el punto de vista del reproche penal, y lo que debemos destacar es que sus acciones no eran espontáneas ni se deducían de la mera necesidad de supervivencia en un momento dado. Así que es lógico que ciertos grupos adquirieran alguna celebridad y en determinados momentos y lugares dieran lugar a denominaciones genéricas, como es el caso de golfines o almogávares, que se hicieron muy populares en su tiempo. Pero, sin duda, nunca actuaron desde el aislamiento; es más, no era raro que su comportamiento transgresor estuviera encaminado por los poderes de la época, a cuyas pautas e intereses respondía. Por eso el fenómeno que nos proponemos diseccionar es claramente coherente con el orden feudal, al cual en absoluto contradice ${ }^{2}$.

1 La bibliografía al respecto es inmensa, tan sólo mencionaremos el volumen editado por A. L. Kaufman, British outlaws of Literature and History, Jefferson, 2011, concretamente la parte III referente a "The Robin Hood tradition".

2 Sabido es que definir un fenómeno tan escurridizo como el bandidaje es empresa harto complicada, y además, como ha advertido B. Pomara Saverino, se corre el riesgo de encerrar un fenómeno complejo dentro de categorías estrechas. Ver su libro Bandolerismo, violencia y justicia en la Sicilia barroca, Madrid, 2011, 
Como es natural hubo en todo momento multitud de delitos cometidos con concurso de autores, pero para verificar la presencia de una banda organizada, tal como antes se ha descrito, no basta con una mera agrupación de personas que pudieran realizar uno o más crímenes, por graves que fuesen. Realmente, los malhechores casi siempre han tenido una cierta tendencia a reunirse para obtener así el respaldo que necesitan, pero eso no es lo que aquí interesa. En las páginas siguientes no vamos a estudiar el delito cotidiano, casi siempre individual y local, sino la violencia depredadora de las bandas, cuya problemática va mucho más allá y nos permitirá encontrarnos con todo un conjunto de problemas relativos a diferentes estratos sociales en sus múltiples vinculaciones.

Teniendo todo esto en cuenta, lo que se propone en el presente artículo es penetrar en la variedad que presentan tales bandas organizadas -independientemente de que sus protagonistas fuesen de origen humilde o no-, con el fin de discernir las características, objetivos, causas y conexiones que tenían. De este modo comprobaremos el alcance de sus actividades y el papel que ejercían en la sociedad, siempre en completa coherencia con el orden feudal de la época, tal como ha quedado indicado.

\section{DATOS Y CONSIDERACIONES SOBRE LOS GOLFINES (SIGLOS XIII-XIV)}

Avanzado el siglo XIII algunos documentos dispersos nos hablan con poco detalle acerca de unos bandidos llamados golfines. Dichos bandidos y sus correrías habrían sido la causa principal que llevó al nacimiento de las hermandades viejas de Toledo, Talavera y Ciudad Real, unas instituciones que perduraron hasta el final del Antiguo Régimen y que para afirmar la legitimidad de su existencia, así como el amparo regio que precisaban, desde muy pronto tendieron a rodear su nacimiento de una atmósfera legendaria. Pretendían con ello destacar la antigüedad de su fundación -exagerando todo lo posible- y, al mismo tiempo, conectar el surgimiento de dichas instituciones con la monarquía y hasta con el pontificado. En realidad, las noticias que aluden específicamente a los golfines son muy escasas y además al mitificar los orígenes hermandinos se contagiaba con ello la propia peripecia de los golfines.

Las ordenanzas de la Hermandad de Ciudad Real de $1792^{3}$ afirmaban que después de la batalla de las Navas de Tolosa desertores, huidos y desmovilizados permanecieron en la tierra cometiendo toda clase de delitos. A una cronología aún más antigua nos llevaría un escrito del Archivo Municipal toledano, con letra del siglo XVIII ${ }^{4}$, en el que se presenta

p. 18. No obstante, cabe tener en cuenta como punto de partida la opinión de F. Segura Urra en cuanto que el bandido puede ser el malhechor que actúa en compañía de otros formando grupos bien organizados y jerarquizados. Ha de consultarse el artículo de este autor "Raíces historiográficas y actualidad de la historia de la justicia y el crimen en la Baja Edad Media", Anuario de Historia del Derecho Español, 73 (2003), p. 635. Es necesario aclarar, por otra parte, que en las páginas que siguen se considerarán las palabras "bandido" y "bandolero" como sinónimas. Sobre dichos vocablos, sus diferencias y evolución ver el artículo de J. Álvarez Barrientos y P. García Mouton, "Bandolero y bandido. Ensayo de interpretación", Revista de Dialectología y tradiciones populares, XLI (1986), pp. 7-58. La difusión de ambos términos es tardía. En este orden de cosas el conocido trabajo de G. Cherubini, "Appunti sul brigantaggio in Italia alla fine del Medioevo", en II lavoro, la taverna, la strada, Napoli, 1997, pp. 144-49, compara las palabras "brigantaggio" y "banditismo". Para contextualizar la temática que proponemos abordar - sin ningún ánimo de convertir esta nota en interminablecabe recordar, por un lado, los estudios reunidos por J. Appleby y P. Dalton, Outlaws in Medieval and Early Modern England: Crime, Government and Society, c. 1066-1600, Farnham, 2009, y por otro, las obras sobre violencia, orden público y caballería de R. W. Kaeuper, entre las que entresacamos War, Justice and Public Order, Oxford, 1988; y Chivalry and Violence in Medieval Europe, Oxford, 1999.

3 Archivo Histórico Nacional (en adelante, AHN), Códice 933B.

4 Archivo Municipal de Toledo, Archivo Secreto, 2, leg. 1, núm. 3. Es un simple borrador que no tiene mayor 
a "salteadores que en este Reyno llaman golfines" moviéndose por las cercanías de la ciudad simultáneamente a los enfrentamientos que tuvieron lugar entre los poderosos Castro y Lara, durante la minoría de Alfonso VIII. Ulteriormente, tan numerosos y atrevidos fueron que llegaron a robar las camas y arcas de plata de Alfonso X cuando iba camino de Andalucía, aunque es Fernando III en versiones más tardías; por cierto que esta narración aparece por primera vez en un documento talaverano de la época de Álvaro de Luna ${ }^{5}$. Otro documento más antiguo, fechado en 1338, indica que hicieron apellido llamándole Mi Carchena, lo que viene a señalar alguna banda más conocida, y a partir de aquí surgió después la idea legendaria de un supuesto rey Carchena, que vivía en los montes de Guadalupe al frente de los malhechores. Del mismo modo, no faltan alusiones a castillos, desde los que lanzarían sus acciones violentas, ni tampoco a la presencia entre ellos de moros, empezando quizá por el propio Carchena ${ }^{6}$. Todas estas tradiciones aunque se han repetido una y otra vez no se apoyan en prueba alguna y nos sirven más para observar los mecanismos legitimadores forjados por las hermandades que para profundizar con certeza en la realidad histórica de los golfines. Además, paulatinamente fueron incorporando influjos procedentes de las formas de bandidaje propias de la Edad Moderna. Sea como fuere, hay que tener muy en cuenta que dichas tradiciones se inician tempranamente y suscitan algunos temas que sí interesa retener, me refiero concretamente a los siguientes: primero, la frontera; segundo, la conflictividad nobiliaria; y, tercero, la existencia en el campo de grupos organizados y numerosos de individuos armados.

En relación con el primero de los tres aspectos citados, podemos comenzar, como ya se ha hecho otras veces, releyendo un párrafo muy breve de la Crónica de Bernat Desclot, un texto catalán que alude a estas bandas en el contexto fronterizo e identifica a sus integrantes como hombres acostumbrados a las armas y originarios de la España interior ${ }^{7}$ :

"Aqueles altres gens que hom apela 'golfins' son castelans e galegos e dins de la profonda Espaya e son la major part de paratge; e per so com no an rendes de que viven, o cor han desgastat o jugat so que an, o per alcuna mala feta, han a fugir de lur terra e ab lurs armes, axí com homens qui abre no poden ne saben fer, van-se'n en la frontera del ports de Muredal, qui són grans muntayes e forts, e gran boscatges, e marquen ab la terra de sarraÿs e dels crestians, e aquèn passa lo camí que va de Castela a Xibília e a Côrdova, e axí aqueles gens roben e prenen de crestians e de sarraÿs, e están en aquels boscs e aquí viuen; e son molt grans gens e bons hòmens d'armes, quel rey de Castela non pot venir a fi".

En conclusión, bandidos de frontera, gentes de aluvión, pero con un denominador común que es su familiaridad con toda clase de armas, y que sobreviven sobre el terreno amparados por la escasa humanización del territorio. Si se mira despacio son notorias las semejanzas entre lo indicado por el cronista y los almogávares que el mismo autor describe. Lo que ocurre es que en torno al camino que de Toledo iba a Córdoba no había forma-

valor como testimonio, pero con posterioridad esta versión ha sido recogida en varias publicaciones.

5 Archivo Municipal de Talavera (en adelante, A. M. Talavera), Santa Hermandad, leg. 24, núm. 8. Este documento atribuye el hecho a Alfonso $X$.

6 Pueden verse al respecto, además de las ordenanzas hermandinas ya citadas, una amplia bibliografía que cabe iniciar citando a A. de Torrejón, Libro de las antigüedades de Talavera, 1596, Biblioteca Nacional (en adelante, BN), mss. 1498, folios 74v-75r; P. Salazar de Mendoza, Monarquía de España, Madrid, 1770, libro III, capítulo XV, pp. 360-61, así como numerosas obras decimonónicas, algunas bastante novelescas.

7 Crónica de Bernat Desclot, editada por M. Coll i Alentorn, Barcelona, 1949, III, p. 627. He citado y utilizado esta información en mi libro Santa Hermandad Vieja de Toledo, Talavera y Ciudad Real (Siglos XIII-XV), Toledo, 1987, p. 33, pero de diferentes maneras se viene utilizando desde hace mucho tiempo. 
ción política musulmana alguna en la segunda mitad del siglo XIII, aunque seguía siendo un territorio poco poblado y sobre el que los poderes de la época ejercían un control no demasiado estricto. Pero podríamos llegar a sospechar incluso que estos golfines fuesen continuación de un fenómeno iniciado tiempo atrás, cuando las condiciones políticas y de inestabilidad militar eran otras, y propiamente cabía decir que el puerto del Muradal era tierra de frontera, como quiere el cronista.

Ya hemos dicho que la documentación de archivo es muy escasa y dispersa pero a pesar de todo nos permite proseguir nuestra indagación en una cronología que abarca la segunda mitad del siglo XIII y los inicios del XIV. Sin embargo, estos pocos escritos lo que no hacen es aportar detalle alguno sobre las características de los golfines. En general, son privilegios reales otorgando imposiciones sobre el paso de los rebaños trashumantes, 0 bien, concediendo lugares, siempre para que determinados poderes feudales sostuviesen la defensa contra la peligrosidad de los salteadores en los espacios montaraces ${ }^{8}$. También las ordenanzas de los colmeneros de Sevilla hechas en 1254 -uno de los textos más antiguos a este respecto- aluden a folguines que "andudieren por la syerra" para acudir tras ellos en expediciones de hasta ocho días de duración. Finalmente, en las Cortes de 1293, al obligar a los concejos a guardar sus términos frente a los malhechores, se contemplaba como excepción que "non sean tenudos de pechar el danno que fezieren los golfines a los pastores quando passaren con sus ganados"10; y unos años antes el mismo Desclot, arriba citado, presentaba a algunos de ellos en el puerto de Tortosa, junto a los almogávares,

8 Confirmación de Fernando IV al concejo de Santisteban de una disposición de su antecesor, fechada a trece de octubre de 1304 y recogida por A. Paz y Melia, Series de documentos del Archivo del Duque de Medinaceli, Madrid, 1915, p. 442, para que guardase el puerto de Montizón cobrando para ello rolda y montazgo; confirmación de Pedro I de un privilegio de 1295 relativo al lugar de Jaraicejo, reg. por L. V. Díaz Martín, Colección documental de Pedro I de Castilla (1350-69), Valladolid, 1997, I, núm. 243; privilegio de Fernando IV, año 1305, dando a Garci Sánchez de Trujillo el lugar de Valdepalacios, AHN., Clero, Pergaminos 396/18. E. Cabrera Muñoz en su trabajo titulado "Del Tajo a Sierra Morena" en Organización social del espacio en la España medieval. La Corona de Castilla en los siglos VIII a XV, Barcelona, 1985, p. 150, cita la concesión hecha por la ciudad de Córdoba en 1293 a Fernando Díaz Carrillo del castillo de Santa Eufemia, a instancias de Sancho IV; y en la nota 54, p. 160, menciona dos documentos al respecto, uno de 1292 referente a Puebla de Alcocer y otro posterior sobre el área de Guadálmez. También el libro clásico de Klein, La Mesta, Madrid, 1979, pp. 98-99 señalaba que la organización ganadera habría tenido que defenderse de los golfines. En I. J. de Ortega y Cotes, J. F. Álvarez de Baquedano y P. de Ortega Zúñiga y Aranda, Bullarium Ordinis Militiae de Calatrava, Madrid, 1761 (edición facsímil, Barcelona, 1981), se contiene una referencia al montazgo que llevaba la Orden por la protección contra los golfines en el camino de Orgaz a Baeza. R. Córdoba de la Llave, El homicidio en Andalucía a fines de la Edad Media, Granada, 2007, p. 101, muestra al conde de Tendilla solicitando al monarca que "mande preguntar a personas que hayan leído [...] algunas mercedes y privilegios de Calatrava y hallarán que ganada la tierra aquende la Sierra Morena quedaron en ella unos malhechores que llamaban holguines, y porque los de la orden de Calatrava los siguiesen tienen de merced muchas rentas". I. Las Heras, en "Algunas precisiones sobre los golfines", Estudios de Historia de España, I (1988), p. 20, toma nota de la donación ya referida del castillo de Santa Eufemia, así como también, menciona que los golfines arrebataron $\mathbf{3 0 0}$ maravedíes a Johan Ruiz cuando trasladaba dinero en el arzobispado de Toledo, y se refiere a la carta puebla de Gibraltar de 1310, donde se alude a golfines como posibles inmigrantes que allí pudieran acudir. J. Pellicer de Tovar, Memorial de la calidad y servicios de la casa de don Álvaro Francisco de Ulloa Golfín y Chaves, Madrid, 1675, folio 101r-v, señalaba que los reyes hicieron concesiones para que se hiciese guerra a los golfines, de manera que Sancho IV dio a Fernán Pérez del Bote [sic] facultad para hacer casa fuerte en la Cabeza de Belvís, con treinta vasallos, de manera que pudiese defenderse de los malhechores, y también otorgó el lugar de Jaraicejo a Pedro Sánchez de la Cámara, pues en la zona habían ocupado el castillo de la "Xara".

9 Archivo Municipal de Sevilla, sección 16, núm. 9. J. M. Sánchez Benito, "Datos sobre la organización de la producción apícola en la Baja Edad Media", Estudis d'Història Económica (1989)-1, p. 14.

10 Cortes de León y de Castilla, I, núm. 10, p. 23. 
para participar en las empresas militares de Pedro III $^{11}$. Como he indicado, todas estas fuentes no aportan detalles pero sí vienen a mostrar que se trata de un fenómeno muy difundido, diríamos que endémico, en un ámbito de considerable amplitud que se extiende a lo largo y ancho del Campo Arañuelo, sierras de Guadalupe, las Villuercas y Altamira, La Jara talaverana y los Montes de Toledo, Puebla de Alcocer, Campo de Calatrava, Chillón, Los Pedroches y toda Sierra Morena, así como zonas periféricas de la tierra de Sevilla. De manera que la expresión "golfines" (o folguines) designaba a malhechores que actuaban en bandas y cuyas acciones dieron lugar al repertorio de daños que tantas veces mencionan los documentos: "mataban los omes et les tomaban lo que traíen y forzaban las mujeres y quebrantaban y quemaban los lugares poblados et facíen otros muchos males"12.

Este es el contexto en el que nacen las tres hermandades de Toledo, Talavera y Villa Real ya mencionadas. Sin embargo, los escritos más antiguos relativos a estas instituciones no van más allá de 1300, y ninguno de ellos da testimonio de su creación sino que vienen a reconocer unas agrupaciones ya existentes. No faltan pues las brumas en este asunto, como en todo lo referente a los golfines, y además entre esa niebla, a partir del mismo siglo XIV, los hermanos dieron pábulo, según se ha indicado, a toda clase de leyendas. Como no podía ser de otro modo, los golfines aparecen de vez en cuando en los documentos procedentes de las referidas hermandades, aunque sólo sean meras alusiones relativas al origen de las mismas. Lo interesante es que muy al principio hablan de ellos en presente y los muestran totalmente activos, causando toda suerte de daños a ganaderos, viajeros y, lógicamente, a quienes encontraban su medio de vida en los espacios silvestres ${ }^{13}$. Unos años más tarde, en 1338, al solicitar a Alfonso XI confirmación de las mercedes que ya tenían, los procuradores hermandinos razonaban que en tiempos de Alfonso $X$ y Sancho IV muchos hombres se habían echado al monte, proliferando el delito. Por primera vez se mencionaba entonces la referida leyenda de Carchena. Lógicamente, cabe pensar que los enfrentamientos acaecidos en la última fase del gobierno del Rey Sabio habrían propiciado la actividad de bandas armadas ${ }^{14}$ que debieron ser numerosas y bien organizadas, según invita a suponer el apellido Mi Carchena. Después, aludiendo a la minoría de Alfonso $\mathrm{XI}$, se volverá a insistir en que durante las turbulencias del reino algunos ladrones se habían internado en los montes ${ }^{15}$. Además, hemos visto con anterioridad que casi toda la documentación de diversa índole referente a los golfines data precisamente de fines del siglo XIII e inicio del XIV, abarcando toda la etapa histórica, particularmente inestable, que llega hasta la mayoría de edad de Alfonso XI. Por lo tanto, son muchos los indicios que hacen coincidir las depredaciones de los golfines con la inestabilidad y la violencia política de Castilla en esta época, de tal modo que si párrafos atrás destacábamos la conflictividad

11 I. Las Heras, "Algunas precisiones...", p. 27, da cuenta de la noticia cronística que muestra cómo Alfonso $X$ encontró grandes grupos de golfines que andaban robando y matando en las montañas y que al reunir su hueste en Córdoba les ofreció el perdón si se incorporaban a ella.

12 AHN, Diversos, leg. 23, núm. 43.

13 Ver por ejemplo la carta dirigida por la ciudad de Toledo a su naciente hermandad en 1300, BN, mss. 13030, folios 115r-17r, publicada por L. Suárez Fernández, "Evolución histórica de las hermandades castellanas", Cuadernos de Historia de España, XVI (1951), pp. 55-57.

14 M. Gaibrois, Historia del reinado de Sancho IV de Castilla, Madrid, 1922, I, p. 19, apoyándose en la crónica de este soberano, señalaba que en 1284, una vez afirmado en el trono, castigó severamente a los golfines.

15 Ambos documentos en BN, mss. 13100, folios 15r-21r y AHN, Códice 818B, folios 37v-39v, respectivamente. Recordemos, a título comparativo, que J. I Ruiz de la Peña, "Realeza y concejos versus ladrones y malhechores: la lucha contra la delincuencia en la Asturias medieval (siglos XII-XIV)", Clío y Crimen, 3 (2006), p. 65, afirmaba que en estos años de la minoría de Alfonso XI las malfetrías de la nobleza asturiana alcanzaron sus máximas cotas en el marco de una situación de verdadero desorden. 
del reino como uno de los factores que rodean a estos bandidos, ahora, con mayor certeza, hemos de confirmarlo.

En este sentido, si ya el primero de los privilegios hermandinos señalaba que los golfines obtenían perdones de maestres, concejos y hasta de la misma corona, en 1320 -siendo Alfonso XI todavía menor- sabemos que los hermanos talaveranos tenían que acudir al concejo de su villa porque sufrían toda clase de querellas y daños por enfrentarse a los golfines. Ocho años más tarde el mismo problema volvió a salir a la luz al haber sido apresados dos hombres de la misma hermandad bajo la acusación de dar muerte a un malhechor ${ }^{16}$. De estas evidencias se deduce que no hay que ver a los golfines como unos seres alejados de todo y de todos, sumergidos en las espesuras silvestres, sino que muchas de sus correrías contaban con la protección de poderosos. Este ambiente de encubrimiento, alrededor de los referidos actos criminales, viene a mostrar que estaban perfectamente integrados en unas redes de protección clientelar en cuyo marco pondrían su espada al servicio de intereses políticos de los más fuertes. No podemos sorprendernos de que esta clase de vínculos, tan habituales en otros contextos, funcionasen con amplitud y vigor al compás de la pugna que enfrentó a Alfonso $X$ con su hijo Sancho, y luego durante las minorías de Fernando IV y Alfonso XI, cuando el choque entre poderosos alcanzó extraordinaria virulencia.

Precisamente hacia el final de dicha etapa de aguda inestabilidad política -entre 1320 y 35 aproximadamente- deja de hablarse de los golfines, y la palabra ya no volverá a utilizarse salvo como un recuerdo del pasado. Es seguro que la mayor estabilidad política del reinado de Alfonso XI, así como la mejor articulación del territorio, en virtud de los procesos colonizadores y la creciente proyección de ciudades como Toledo, Talavera o Córdoba, tiene mucho que ver con el final de estas bandas. Ya sabemos que las hermandades se atribuyeron el mérito de su desaparición, pero importa tener en cuenta que, al fin y al cabo, ellas mismas -cuyas cabeceras estaban en Toledo, Talavera y Ciudad Real- no dejan de ser una faceta más de la proyección urbana sobre estos espacios.

Así pues, la peripecia histórica de los golfines se explica a la luz de una serie de factores que podemos identificar perfectamente: a) la geografía montuosa y escasamente humanizada que acoge sus fechorías; b) el carácter fronterizo que dicho territorio había tenido durante mucho tiempo; c) la conflictividad política y las pendencias nobiliarias que entre la segunda mitad del siglo XIII y principios del siguiente dieron vida a las bandas y facilitaron sus correrías.

\section{ALMOGÁVARES Y BANDIDAJE FRONTERIZO (SIGLOS XIII-XV)}

Mucho más conocidos son los almogávares, que por sus similitudes con los golfines -según las descripciones de Desclot- han sido ya mencionados más arriba. Como quiera que sus características se han divulgado sobradamente no procede que aquí nos extendamos sobre ellos. A tenor de crónicas como la mencionada, se trata de hombres de frontera, cuyos orígenes podrán ser variados pero no así sus costumbres rústicas y forma de vida extremadamente dura. Perfectamente insertos en la geografía que les da cobijo, podían moverse con rapidez y no era raro que penetrasen muy profundamente en el territorio granadino, siempre buscando el botín que les permitía sobrevivir; del mismo modo que salían eficazmente al paso de las incursiones musulmanas. No sorprende que contaran a menudo

16 A. M. Talavera, Santa Hermandad, leg. 23, núm. 2 y AHN, Códice 818B, folios 26v-30v., documento publicado por J. M. Sánchez Benito, Colección de documentos de la Santa Hermandad (1300-1500), Toledo, 1990, núm. 13. 
con apoyo de los poderes instalados en los castillos y plazas fuertes de la zona. Como se sabe, la bibliografía es copiosísima, especialmente sobre su participación, como eficientes y temidos guerreros, en el conflicto de Sicilia y, en general, en la expansión mediterránea de la Corona de Aragón, pero nada de todo ello interesa en este artículo ${ }^{17}$. En todo caso, hay que tener en cuenta que también se mencionan almogávares en el ámbito murciano, entre Castilla y Valencia.

La palabra "almogávar" define, por consiguiente, al depredador de frontera, incluyendo siempre a personajes violentos pero de características no necesariamente idénticas, pues si la imagen clásica, que arriba se ha indicado, es la que transmiten las grandes crónicas catalanas, en el presente artículo hemos de fijarnos más bien en la perduración de gavillas de hombres que recibieron este nombre y se dedicaron al pillaje durante los siglos XIV y XV en el marco de las condiciones fronterizas y la amplitud de unos espacios en los que la población era muy reducida ${ }^{18}$.

Pero no nos entretengamos en consideraciones generales e intentemos concretar en lo posible. M. T. Ferrer i Mallol cita varios asaltos a carniceros y ganaderos ocurridos en los años veinte del siglo XIV en el ámbito que se extiende entre Alcaraz y Elda, apresando de paso -en una ocasión- a los pastores que cuidaban las reses. Los responsables fueron grupos de castellanos y murcianos ${ }^{19}$. Se sabe, por otra parte, que bastantes años más tarde hubo una queja de la villa de Almansa alegando que por su situación en frontera "se fazían y muchos cativamientos et salteamientos et muertes por moros et almogávares"20, y sin alejarnos en el tiempo se formó una hermandad a principios del siglo XV entre Villena y Sax "por razón de algunos malos omes almogávares que salteavan e furtavan los omes"21. En fin, cabría prolongar la relación de sucesos, pero no tiene mucho sentido. Lo cierto es que en el referido sector fronterizo, entre las coronas de Castilla y Aragón, permaneció durante largo tiempo el fenómeno que estamos observando, protagonizado tanto por castellanos como por valencianos. Son los "omes malos almogávares"22, cuyo modus operandi consistía en asaltos rápidos realizados por pequeños grupos, de unos diez hombres, que contaban con informadores locales, encubridores, etcétera, sin que faltasen caballeros que desde los castillos comarcanos amparaban estas correrías a cambio de beneficio. Tales

17 Puede encontrarse un buen resumen en M. T. Ferrer i Mallol, "Els almogàvers a la frontera amb els sarraïns en el segle XIV", L'Avenç, 209 (1996), pp. 14-19. También se denominan almogávares los musulmanes que protagonizaban profundas razias y que con facilidad podían llegar, incluso, a la Corona de Aragón, atravesando la franja de Murcia.

18 J. Torres Fontes en su artículo "Los fronterizos murcianos en la Edad Media", Murgetana, 100 (1999), pp. 12-13, tras recordar a los dos almogávares de Lorca que, según la cronística, fueron a Jaime I para informarle sobre movimientos de fuerzas musulmanas, indica que en el contexto murciano de esta época "el almogávar lorquino no sería el que tan minuciosamente describe Muntaner de los almogávares aragoneses".

19 M. T. Ferrer i Mallol, Entre la paz y la guerra. La Corona Catalano-aragonesa y Castilla en la Baja Edad Media, Barcelona, 2005, pp. 323-25.

20 Por lo cual existía una fuerza de caballeros y ballesteros desde los tiempos del infante Juan Manuel. A. Pretel Marín, Almansa medieval. Una villa del señorío de Villena en los siglos XIII, XIV y XV, Albacete, 1981, pp. 80-81. También se habla de almogávares más al norte, en el área de Chinchilla, en la primera mitad del siglo XV, A Pretel, Chinchilla medieval, Albacete, 1992, p. 192, y a la presencia de almogávares foráneos entre Chinchilla y Ayora se refiere un documento de 1453 que publica este mismo autor entre las pp. 533 y 34, núm. 19.

21 J. M. Soler García, "Aportación documental a la historia albacetense en los siglos XIV y XV", Congreso de Historia de Albacete. Edad Media, Albacete, 1984, publica, con el núm. 3, un documento para que dicha hermandad, que llevaba dos años, se prorrogase.

22 Expresión que recoge J. Bernal Peña, "Golfines y asesinos. Marco legal del delito durante la Edad Media. Detalles de Murcia durante el siglo XIV", Miscelánea Medieval Murciana (M.M.M.), XXXV (2011), p. 38. 
grupos, aunque eran más o menos variables, tenían una organización y un liderazgo bien asentados, y podían incluir simultáneamente a individuos procedentes de ambos reinos, los más de vida inestable y rufianesca. En el botín se incluía ganado -no exclusivamente-, objetos diversos, y además el secuestro se fue abriendo paso como una actividad particularmente lucrativa. En este último aspecto todo indica que los mencionados grupos delictivos seguramente no eran más que el primer peldaño de unas tramas de venta de esclavos bastante complejas que se apoyaban precisamente en la divisoria entre los dos reinos y en la proximidad de Granada ${ }^{23}$.

Sin entrar en la problemática específica de los confines granadinos ${ }^{24}$, seguiremos atentos a la vida fronteriza porque se ha repetido casi hasta la saciedad que favorece la proliferación del bandolerismo y por ello intentaremos comprobar en qué medida y de qué manera puede ser esto cierto. Si desplazamos nuestro foco de atención desde el ámbito murciano hacia el norte, al llegar a la tierra de Molina, colindante con la Corona de Aragón, un memorial fechado tardíamente ${ }^{25}$-ya a principios del siglo XVI- señala que muchos malhechores habían encontrado allí refugio precisamente por la proximidad de la frontera. En realidad, la inestabilidad de la centuria anterior había favorecido este hecho y la inseguridad se había visto acrecentada por la presencia de vizcaínos poco arraigados que trabajaban en los filones de hierro de la zona ${ }^{26}$. Entre la villa citada y la de Moya hay noticias de la segunda mitad del siglo XV acerca de individuos que encontraban cobijo en los montes y con facilidad huían atravesando los linderos entre reinos. El ganado era objetivo principal por su movilidad. En 1460 se decidió en Cuenca ofrecer recompensa a los que consiguiesen capturar a los autores de estos robos $^{27}$ y en los tiempos inmediatos todo indica que el problema arrecia, lo cual nos lleva a ponerlo en relación con la inestabilidad del momento. En el mismo año mencionado se hizo hermandad entre Cuenca, Moya y Requena en cuya carta se preveía la intervención de "algund señor o cauallero poderoso" a favor de los referidos malhechores, que estaban, se indica, escondidos en los barrancos y actuaban ocultos tras barbas postizas y caretas, contando con el apoyo de otros individuos que les llevaban abastecimiento $^{28}$. De manera que se movían rodeados de complicidades y ello excluye la

23 Es particularmente interesante en todos estos aspectos el trabajo de J. V. Cabezuelo Pliego, "El negocio del rapto en la frontera de Orihuela a principios del siglo XIV", M.M.M., XXI-XXII (1997-98). En el artículo se analizan con cuidado determinados casos de secuestro de moros en el área de Orihuela y en lo que se refiere a la configuración de estos grupos destaca su dirigente, un tal Martín de Jódar, cuyo perfil ejemplifica muy bien lo arriba indicado, p. 55

24 En distintas ocasiones E. Cabrera Muñoz ha hecho breve mención al papel de la frontera granadina en el elevado grado de violencia y delito de la Andalucía tardomedieval. Ver sus trabajos "Sobre la violencia en Andalucía durante el siglo XV", en La Península Ibérica en la era de los descubrimientos, 1391-1492. Actas III Jornadas Hispano-Portuguesas de Historia Medieval, Sevilla, 1997, II, pp. 1064-65; y "Violencia urbana y crisis política en Andalucía durante el siglo XV", Aragón en la Edad Media. Sesiones de trabajo, IV Seminario de Historia Medieval. Violencia y conflictividad en la sociedad de la España bajomedieval, 1995, p. 6.

25 M. Diago Hernando, "Relaciones de poder y conflictos políticos en Molina y su Tierra durante el reinado de los Reyes Católicos", Wad al Hayara, 20 (1993), p. 131.

26 M. Diago, citado en la nota anterior, afirma en la p. 138 que la aspereza de la topografía fronteriza con Aragón "favoreció su conversión en auténticos nidos de malhechores y bandoleros, según reconocieron los propios contemporáneos, que denunciaron además que la instalación de vizcaínos en las herrerías distribuidas por las sierras agravaba aún más la inseguridad de esta comarca". Insiste en estas mismas ideas M. E. Cortés Ruiz, Articulación jurisdiccional y estructura socioeconómica en la comarca de Molina de Aragón a lo largo de la Baja Edad Media, tesis doctoral, Madrid, Universidad Complutense, 2000, p. 693.

27 Archivo Municipal de Cuenca (en adelante, A. M. Cuenca), leg. 195-1, folio 8v.

28 A. M. Cuenca, leg. 195-1, folios 23v-25r. J. M. Sánchez Benito, "Hermandades concejiles en la frontera oriental de Castilla (siglo XV)", en Mundos medievales. Espacios, sociedades y poder. Homenaje al profesor 
posibilidad de que se tratase de meros delincuentes refugiados en los montes fronteros. Se trata más bien de un fenómeno de mucho mayor alcance, que hay que entender en el marco de la inestabilidad política de la época. Lo que subyace, al final, es la violencia de los poderosos al compás de la conflictividad y la aguda competencia política. Dicha violencia se manifiesta, entre otras cosas, a través de bandas de hombres armados que se movían a su sombra ${ }^{29}$.

En todo caso, el problema trascendía al otro lado de la raya, de forma que a Cuenca llegaba carta de Albarracín en 1471 con una propuesta de hermanamiento por los muchos males que se estaban produciendo -entre los que no faltaban, por otra parte, cabalgadas mutuas protagonizadas por nobles y concejos-y en 1476 los Reyes Católicos confirmaban otra hermandad integrada por localidades de ambos lados de la divisoria con fines de pacificación de la misma: "porque los malos omes fuesen punidos e castigados"30. Esta misma zona, y en el contexto de las muchas disputas políticas que asolaron el reino de Castilla a lo largo del siglo XV, permite ejemplificar muy bien cómo la frontera sirve de apoyo a las fuerzas que intervienen en los referidos conflictos, posibilitando que desde Aragón partiesen peligrosas cabalgadas e incluso verdaderos ejércitos con unos objetivos eminentemente políticos, pero de cuyas actividades se deducen no pocas depredaciones de bienes, cosechas y ganados. Ahora bien, aunque estos hechos daban ocasión al movimiento de bandas, nos limitaremos a constatar su existencia sin profundizar en la problemática que todo esto encierra ${ }^{31}$.

Pero donde se ha consagrado plenamente la expresión "frontera de los malhechores" es en el ámbito vasco-navarro, especialmente en el sector guipuzcoano, donde las incursiones depredadoras adquieren una espectacularidad indudable y, por lo tanto, el fenómeno ha sido analizado de manera profusa y acertada ${ }^{32}$. Si ya en 1261 hay noticia de encuentros con asistencia de navarros, guipuzcoanos y alaveses, para evaluar los daños que sufrían las poblaciones colindantes; después las expediciones depredadoras abundan sobremanera, siempre con el ánimo de obtener botín y buscar refugio al amparo de la condición fronteriza del territorio. Con altibajos, su desarrollo llegará a alcanzar el siglo XVI.

José Ángel García de Cortázar y Ruiz de Aguirre, Santander, 2012, II, pp. 1883 y ss.

29 Sobre el contexto de conflictividad y relaciones de poder en estas tierras durante el siglo XV, mi artículo "Violencia y pugna política. Estudio de sus repercusiones en el mundo urbano a través del caso de Cuenca (siglo XV)", Studia Historica. Historia Medieval, 30 (2012), pp. 237-262.

30 J. M. Sánchez Benito, "Violencia y señorialización del territorio realengo en el siglo XV. Datos y consideraciones en el caso de Cuenca", Lope de Barrientos, 5 (2012), p. 139. J. M. Berges Sánchez, Actividad y estructuras pecuarias en la comunidad de Albarracín (1284-1516), Teruel, 2009, p. 107, aludiendo a un convenio de 1328 entre Albarracín y Molina afirma que "este acuerdo no es ni más ni menos que una de las frecuentes juntas o hermandades que a lo largo de los siglos XIV-XV se realizaron entre las tierras de Albarracín y las vecinas poblaciones de Castilla para frenar los abusos de salteadores y bandoleros favorecidos por tiempos de suma inestabilidad política".

31 Tampoco entraremos en los casos de contrabando que incluían el uso de la violencia: grupos que viéndose sorprendidos se defendían arma en mano, ataques a los guardas que llevaban algún preso o incluso represalias contra los que debían evitar los tráficos clandestinos. Todo esto conforma un universo muy peculiar, propicio a la formación de bandas y que requiere un análisis específico. Algunos apuntes en mi libro La Corona de Castilla y el comercio exterior, Madrid, 1993, pp. 130 y ss. Más reciente el trabajo monográfico de V. Medrano Fernández, "El contrabando en la frontera castellano-portuguesa en el siglo XV. Un estado de la cuestión", en La Península Ibérica entre el Mediterráneo y el Atlántico (siglos XIII-XV), Sevilla-Cádiz, 2006. 32 Ver especialmente el esclarecedor artículo de J. R. Díaz de Durana y J. A. Fernández de Larrea, "La frontera de los malhechores: bandidos, linajes y villas entre Álava, Guipúzcoa y Navarra durante la Edad Media", Studia Historica, 23 (2005), pp. 171-205. 
Se conocen bien sus formas de actuación a través de una documentación del siglo XIV estudiada por Javier Zabalo ${ }^{33}$. Eran grupos relativamente pequeños que apoyándose en extensas redes de complicidades, se movían preferentemente con nocturnidad y mataban si tenían que reducir la resistencia de los agredidos. Imponían evidentemente una atmósfera de miedo en las comunidades locales y, sin descartar el asalto a los arrieros de paso o la práctica del secuestro, tenían como objetivo principal la sustracción de ganado. En parte lo consumían directamente o bien procedían a su venta o cobraban rescate a los dueños. Por lo que se refiere a los protagonistas, en la citada encuesta se distinguen los "malhechores de Albizu", no más de veinte hombres que habrían venido actuando durante otros tantos años. A su frente Garci López de Albizu, cuyo padre había hecho lo mismo, que contaba con una torre y se llevaba la mitad del botín. Por otra parte, los guipuzcoanos conectados con la casa de Lazcano, unos cuarenta en total. Todo indica pues que el pillaje era para esos hombres una forma de vida, así como el mecanismo económico que financiaba estas comitivas. En definitiva, bandidaje fronterizo propiamente dicho que, al compás de la competitividad política, se verá agravado por las rivalidades de los linajes banderizos -para los cuales la frontera era muy permeable- y en el cual inciden de manera determinante las redes clientelares que funcionaban a ambos lados. Es natural que en esta dinámica la venganza fuera secuela inevitable.

Así pues, hemos realizado un periplo que nos ha llevado desde el siglo XIII al final del $\mathrm{XV}$, y de sur a norte siguiendo el trazado de los confines orientales de Castilla. Primero los golfines, cuyo origen acaso pudiera llevarse a los tiempos de la repoblación y que, según lo que se ha visto, nos plantean ya unos problemas que después se van a reiterar con mayor nitidez: 1) grupos bien jerarquizados, compuestos por un número de miembros que acaso no fuese tan elevado como las fuentes parecen indicar cuando aluden a la peligrosidad de estos bandidos; 2) el territorio montuoso y poco organizado; 3) la conflictividad política, con arreglo a la cual oscila siempre la virulencia de las bandas; y teniendo en cuenta este último factor, 4) la inserción de los malhechores en las redes clientelares existentes, aunque fuese a un nivel relativamente difuso. Similares a los golfines, los almogávares, cuya pista hemos seguido brevemente en el ámbito murciano centrándonos principalmente en los años trescientos e incluso cuatrocientos. Cuando hablamos de ellos pareciera que los aspectos que acabamos de enumerar hace un instante se repiten estrictamente (el territorio, la conflictividad...). Pero en este caso las investigaciones que se han llevado a cabo permiten afirmar -sin las oscuridades que encontrábamos en el caso de los golfines- que las redes en que están sumergidos son realmente extensas y llegan a adquirir verdadera complejidad. Además, se constata efectivamente que los grupos están integrados por gentes de aluvión, como ocurrió, sin duda, en el caso de los golfines. La verdad es que al comparar unos y otros, golfines y almogávares, se siente la tentación de pensar que se trata de un mismo fenómeno, designado con dos palabras distintas, según las regiones y los momentos, y que tiene una mayor perduración en la frontera sureste del reino castellano, precisamente porque a caballo entre dos reinos y con una densidad demográfica endeble, el control del espacio por fuerza era siempre escaso.

Más al norte, en el sector Molina-Cuenca-Moya-Requena, la información que tenemos nos lleva al siglo XV, no antes; y allí las montañas permiten la ocultación de unos grupos que actúan claramente a la sombra de los poderosos en las difíciles condiciones políticas que son propias de los reinados de Juan II y sobre todo de Enrique IV. Sólo a partir de la

33 J. Zabalo Zabalegui, "Una encuesta de 1369 sobre bandidos navarros y guipuzcoanos", Príncipe de Viana, 229 (2004), pp. 480-90. También J. R. Díaz de Durana y J. A. Fernández de Larrea, "La frontera de los malhechores", pp. 180-82. 
inestabilidad política pueden entenderse los datos que en este punto han quedado expuestos antes. Y aún más al norte, en los linderos con Navarra, lo que encontramos es de nuevo una continuidad delictiva que parte del siglo XIII y se prolonga con altibajos en íntima relación con las redes clientelares de la zona y los intereses de los parientes mayores. En fin, siempre el pillaje como forma de vida, en relación con unos factores fundamentales que se reiteran una y otra vez. No otro es el cimiento que daba vida -de una u otra forma- a la violencia en banda. En cuanto a la forma de llevarse a cabo dicha violencia, responde en todos los casos a la acción de grupos relativamente pequeños, dotados de una gran movilidad que les permite aparecer y desaparecer con rapidez. Tal es, desde luego, característica sempiterna del bandidaje. Por lo demás, los grupos nunca actúan en solitario, sino sobre la base de amplias complicidades, y capturan cuanto se les ofrece, especialmente ganado por razones obvias. Realmente están bien insertos en el entramado socio-político, dentro del cual resultan perfectamente funcionales.

\section{NOBLES Y BANDAS ARMADAS (SIGLOS XIV-XV)}

Volviendo al interior peninsular, muy cerca del área de actuación de los golfines, noticias cronísticas de la época de Alfonso XI aluden a un personaje en el que es oportuno reparar por un momento. Me refiero a Egas Páez, que al frente de sus malhechores aterrorizaba los caminos robando, matando y forzando mujeres. No fue fácil eliminarlo hasta que en 1329 fue finalmente capturado en Santa Olalla, desde donde operaba, y ajusticiado con sus hombres por orden del soberano. Aunque la información al respecto es realmente poca, ha sido citado en distintas ocasiones por numerosos autores y se puede aceptar que su actividad depredadora tenía un fin que desbordaba la mera captura de botín. En realidad, presenta una dimensión política muy clara en el marco de los conflictos del momento, a tenor de los intereses de la alta nobleza que en ellos venía participando. En este caso la citada villa estaba situada en la órbita de los Manuel. Por lo tanto, se trataba simple y llanamente de ejercer una proyección sobre la tierra, estratégicamente favorable a un bando, agrupando para ello a individuos seguramente de aluvión, tal como hemos visto en casos anteriores $^{34}$. Al final, el rey actuó para imponer su autoridad en el ámbito geográfico afectado, y lo hizo decisivamente. Tan cerca de Toledo quizá no quedaba otro remedio. Poco más tarde, en 1335, un documento real afirmaba que a causa de la guerra iniciada por Juan Martínez algunos ladrones se habían internado en La Jara y Montes de Toledo movilizándose contra ellos las hermandades ${ }^{35}$.

Acaso no fue muy distinto, a principios de la misma centuria, el caso de Gutierre Ruiz de Vera y su gente, en el área de Uceda. Pero si del anterior solamente ha quedado breve

34 Por eso ha sido calificado como bandido político, Ó. LÓPEZ GÓMEZ, "Violencia, bandidismo y vida campesina en el arzobispado de Toledo: Uceda y su comarca a principios del s XIV", Wad-al-Hayara, 31-32 (2004-05), p. 12. El mismo autor se refiere al tema en su libro La sociedad amenazada. Crimen, delincuencia y poder en Toledo a finales del s XV, Toledo, 2006, pp. 349-50; y en "Abusos de poder y desacato a la justicia en el ámbito urbano medieval: Toledo (1085-1422)", Historia. Instituciones. Documentos, 32 (2005), p. 23031. También recogieron la noticia, entre otros, J. Valdeón, Los conflictos sociales en el reino de Castilla en los siglos XIV y XV, Madrid, 1979, p. 63; y S. Moreta Velayos, Malhechores-feudales. Violencia, antagonismos y alianzas de clases en Castilla, siglos XIII-XIV, Madrid, 1978, p. 92, aunque este autor suponía que se trataba de bandoleros comunes. En mi libro Santa Hermandad..., p. 40, también me he referido al tema. Sabido es que la cronística de la época utiliza la expresión caballeros-malhechores, pero en estos casos cabría preguntar "¿cómo medir en donde acaba el bandolerismo nobiliar y en donde empieza el de las simples bandas de malhechores?", tal como hacía hace años I. Beceiro en su librito La rebelión irmandiña, Madrid, 1977, p. 102.

35 AHN, Códice 818B, folios 37v-39v. 
huella cronística sin apenas detalle, cabe contar ahora con documentación de archivo que ha sido convenientemente analizada por Óscar López Gómez ${ }^{36}$. Es una pesquisa en cuyas páginas se va desgranando una larga lista de acciones - generalmente robos con violenciaconcentradas en un espacio temporal muy reducido. El botín no debió ser pequeño, pero seguramente destaca más el miedo que se consigue implantar en la zona y la condición de enemigos del rey que se atribuye a Gutierre Ruiz y los suyos.

Si los ejemplos anteriores se enmarcan en las dificultades políticas por las que atravesó Castilla en las primeras décadas del siglo XIV, avanzando hacia la centuria siguiente se puede percibir muy bien la correlación que existe entre la frecuencia de sucesos violentos protagonizados por bandas armadas de diversa índole y la inestabilidad del reino. Yo mismo comprobé, siguiendo la documentación de la Hermandad de Talavera, que en el período 1462-73, iniciado con severas dificultades económicas y que incluye a continuación los llamados "años rotos" del reinado de Enrique IV, no solamente se observan delitos más abundantes sino que son más graves y participan en ellos grupos armados ${ }^{37}$, que es lo que aquí interesa. Lo mismo ocurre poco después, al comenzar el reinado de los Reyes Católicos, y más tarde Mendoza Garrido verificó que la acción de bandas se incrementa enormemente alrededor del conflicto de las comunidades ${ }^{38}$. Pero para comprender mejor lo que acabamos de decir se ha de tener en cuenta que los historiadores que han estudiado la delincuencia castellana, principalmente del siglo $\mathrm{XV}$, se han encontrado frecuentemente con que la documentación policial y judicial que utilizan les pone en contacto con pocos casos en los que el protagonismo de los actos delictivos corresponda a bandas armadas ${ }^{39}$ -lo que, por cierto, siempre encierra una mayor gravedad penal-, predominando una criminalidad distinta, de carácter más individual y local, y -digámoslo así- de menor calibre ${ }^{40}$.

Esta escasa presencia de bandas en las fuentes, así como las propias características de los documentos dificultan al extremo la identificación de bandidos de origen popular moviéndose al margen de los intereses nobiliarios. Como es natural, de vez en cuando aparecen en los citados testimonios delitos violentos realizados en el campo por varios autores. Tales delitos tuvieron lugar en las más diversas circunstancias, pero se trata a menudo de grupos ocasionales y en la mayoría de las ocasiones es difícil relacionarlos con el bandidaje. A veces los estudiosos pueden orientarse al encontrar la expresión "salteador", que alude al asalto en camino mediando siempre la violencia. Cabe contraponer a la citada expresión el genérico "ladrón" que se dedica al delincuente más habitual, dedicado al hurto, el robo o la agresión, pero sin la peligrosidad y la organización que muestran las bandas. El salteador es la viva imagen de la violencia más grave en despoblado, interceptando el paso

36 Ó. LÓPEZ GÓMEZ, "Violencia, bandidismo y vida campesina...".

37 Ver mi artículo "Hermandades y delincuencia rural entre el Tajo y sierra Morena (siglos XIII-XV)", Clío y Crimen, 3 (2006), p. 155.

38 J. I. Mendoza Garrido, Delincuencia y represión en la Castilla bajomedieval, Granada, 1999, pp. 197, 323-24 y 346-49.

39 A la limitación de las fuentes de carácter judicial para el estudio del bandidaje medieval se refirió G. Cherubini, "Appunti sul brigantaggio in Italia alla fine del Medioevo...", pp. 141-42. Este autor llega a indicar que mientras en otras fuentes italianas pareciera que el bandolerismo es casi omnipresente en caminos, bosques y campos; en cambio, siguiendo los documentos judiciales es como si no existiese.

40 Cabría citar al respecto, entre otros, a R. Córdoba de la Llave, El homicidio en Andalucía..., p. 101; lo mismo se deduce de las cuentas de la Hermandad de los Reyes Católicos conservadas en Simancas que estudié hace años en mi artículo "Criminalidad en época de los Reyes Católicos. Delincuentes perseguidos por la Hermandad", en Estudios de Historia Medieval en homenaje a Luis Suárez Fernández, Valladolid, 1991; y si prestamos atención a las tres hermandades de Toledo, Talavera y Ciudad Real, la impresión que se obtiene es idéntica. 
de transeúntes o quebrantando incluso las viviendas, aunque con la información que suelen proporcionar las fuentes no es fácil determinar la posición social de los protagonistas de esta clase de sucesos. Sería el caso de tres individuos que en los años noventa del siglo XV actuaban en el ámbito de Guadalajara y fueron perseguidos por la hermandad castellana. La contabilidad de dicha institución se refiere a ellos y, aunque ofrece una información de lo más escueta, nos permite saber que se les acusaba de robos, "salteamientos de caminos" y ocho muertes, a lo largo de sus correrías durante dos años. Posiblemente era una asociación espontánea de forajidos que se dedicaban al delito, sin que nada nos indique su dependencia de poderosos, pero la parquedad de los datos impide descartar por completo tal dependencia, así como averiguar algo sobre su origen. Por otra parte, en las cuentas que nos sirven de apoyo se ve con facilidad que esta clase de sucesos son verdaderamente escasísimos ${ }^{41}$.

Realmente es difícil identificar de manera adecuada a los salteadores y ni siquiera sabemos, muchas veces, si un individuo inmerso en delitos violentos lo era efectivamente. En las fuentes aparecen a veces personajes como un "mancebo suelto que anda por aquí a las veces e otras veces fuera como vagamundo" 42 , acusado ante el corregidor de Cuenca porque tenía que ver con robos en las montañas limítrofes con Albarracín. Individuos de esta clase se beneficiaban de las soledades serranas y de las querellas entre localidades fronterizas, pero difícilmente podrían actuar en solitario. Claro que nada sabemos en concreto ni se puede afirmar que actuasen en el marco de bandas armadas jerarquizadas, que son las protagonistas de este artículo.

Pero si se miran bien las cosas, pronto se da uno cuenta de que la forma de ejercer la violencia que veíamos en los casos que hemos ido observando con anterioridad no se diferencia en realidad del modo en que escuderos y peones dirimían los muchos enfrentamientos que se desarrollaron por toda Castilla en la baja Edad Media, intentando sacar ventaja para sus señores en los conflictos del reino. Como se sabe, la disputa por el poder dio lugar a conflictos casi constantes durante esta época, fruto de los cuales fue una violencia que, siempre por iniciativa de miembros de la nobleza, se reproducía con la mayor frecuencia en los diferentes rincones del reino. En lo fundamental tal violencia se desplegaba a través de rápidas cabalgadas, emboscadas y acciones rápidas en los pueblos, llevadas a cabo por pequeños grupos de jinetes y peones que se apoyaban en las torres y fortalezas de los nobles implicados y se movían con verdadera rapidez. Sus acciones daban lugar a asaltos a caminantes y mercaderes, irrupciones en los pueblos y quebrantamiento de viviendas, secuestros, tomas de ganado incluso en gran cantidad, etcétera. En realidad, estos pequeños grupos no podían llegar a todas partes, pero sí eran capaces de gravitar durante largo tiempo en áreas de considerable extensión y, desde luego, en sus intervenciones siempre estaba muy presente la depredación y el botín. De esta manera, el robo se convertía en un medio para que los rivales enfrentados en la disputa política pudiesen proyectarse sobre el territorio y demostrar a todos su fuerza. Es lo que cabe llamar "guerra en migajas", en el curso de la cual no se buscaba tanto el combate resolutivo cuanto el control del territorio a base de correrías ${ }^{43}$. Conviene recordar que al referirse a estos hechos las gentes que los

41 Se hace referencia a este caso en mi trabajo "Criminalidad en época de los Reyes Católicos...", p. 418. También se menciona (p. 421) algún episodio de particular dureza en ocasión de la persecución y captura, por ejemplo, de dos malhechores que quedaron cercados en un monte de Otero de las Dueñas. Fue preciso reunir un buen contingente que se vio obligado a utilizar las armas que llevaban.

42 A. M. Cuenca, 195-5, folios 139v-40r.

43 No hace mucho he tratado monográficamente estas cuestiones en mis artículos "Violencia y pugna política..." y "Violencia y señorialización...". He tenido presentes ambos trabajos al redactar estas líneas. 
vivían solían utilizar expresiones como "robos", "fuerças", "cohechos", "sinrazones" o "estorsiones"; y era frecuente -al menos en el siglo XV-que, pasado el conflicto en el que tales desmanes habían ocurrido, se iniciasen procesos judiciales en relación a los daños producidos, tanto por iniciativa individual como concejil. Por eso las fuentes de origen municipal resultan particularmente interesantes en estos aspectos.

En el contexto que acabamos de mostrar surgen personajes característicos, como Íñigo López de Mendoza, comendador de Huélamo y hermano segundón del poderoso Juan Hurtado. De este personaje hubo bastantes quejas por realizar toda clase de "robos" desde el castillo de su encomienda, especialmente ganado que luego podía vender en el vecino reino de Aragón. A partir de 1461 edificó torre en una aldea llamada Sotos, cerca de la ciudad de Cuenca, situando allí hombres armados que desplegaron gran actividad, entre otras cosas presionando a los lugareños mediante amenazas, reclamaciones de dineros y llevándose paja, asnos y hasta quinientas cabezas de ganado. Así que primero la depredación pura y simple, al modo de un malhechor-feudal típico que realiza "malfetrías", aunque ya hubiese caído en desuso esta palabra ${ }^{44}$; y más tarde el deseo de imponerse en un lugar realengo con el objetivo de hacerse con él y formar así un señorío. Pero hay más, porque todo ello se hacía paralelamente a los actos de fuerza que por entonces realizaba su hermano, ya citado, junto con otros nobles, al hilo de la conflictividad que asolaba el reino entero y que en un plano más local se traducía en la pugna de bandos que enfrentaba en Cuenca al linaje Mendoza con el obispo Lope de Barrientos. De modo que el comendador actúa en el marco de una facción con unas finalidades eminentemente políticas. A continuación, en el transcurso de la crisis del reinado de Enrique IV, Juan Hurtado y el propio comendador íñigo López realizaron constantes actos de agresión, e irrumpiendo desde casi todas las direcciones depredaron la tierra de forma intensa ${ }^{45}$.

Indudablemente el ejemplo expuesto no representa ninguna excepción, y desde luego la dimensión política siempre está presente en estos actos; pero es conveniente subrayar que la depredación era siempre parte principal de las agresiones armadas, al punto que prácticamente configuraba los propios hechos violentos. A través de la bibliografía cabe encontrar gran número de casos similares, aunque no perderemos tiempo y espacio en pormenores. Me conformaré con recordar, por las mismas fechas, al caballero de Motos, en la tierra de Molina, que desde la torre que tenía participaba activamente en la pugna de facciones y aprovechando la proximidad de la frontera aragonesa robaba a los ganaderos que trashumaban desde el reino vecino y desplegaba toda clase de incursiones depredadoras $^{46}$. Cabe citar también, entre otros muchos casos del siglo XV, las fechorías de Gonzalo

\footnotetext{
Seguramente existe cierta tendencia a asimilar guerra y movimientos de ejércitos numerosos, encaminados a destruir la fuerza del adversario, pero en la etapa histórica que estamos viendo era mucho más frecuente que los conflictos se prolongaran largo tiempo a través de la multiplicación de actos como los arriba indicados. 44 Hace años S. Moreta Velayos, Malhechores-feudales..., consagró la expresión "malhechor-feudal”. El término "melfetría" se utilizaba con relativa frecuencia desde el siglo XIII siempre en relación a la actividad violenta de los nobles. En el siglo XV no se encuentra en la documentación.

45 Y junto a ellos otros personajes como el comendador Juan de la Panda, que actuaba desde la fortificación de Torrebuceit. Ver estas cuestiones en mi artículo citado "Violencia y señorialización...", pp. 129-30. Cabría enumerar multitud de hechos parecidos, pero solamente mencionaremos un caso de 1476 que nos recuerda Ó. López Gómez, "Claves del sistema de pacificación ciudadana desarrollado por los Reyes Católicos en Toledo (1475-1485)", En la España Medieval, 27 (2004), p. 183. Por entonces, un pregón toledano muestra la queja de algunos vecinos de la ciudad porque hombres de Pedro López de Ayala y sus aliados, que estaban desterrados fuera de la misma, les atacaban en los caminos.

46 J. M. Berges Sánchez, Actividad y estructuras pecuarias, p. 117; y M. E. Cortés Ruiz, Articulación jurisdiccional y estructura socioeconómica, pp. 669 y 1272. En este ejemplo también está presente el deseo
} 
Mejía, señor de Santa Eufemia, asaltando con sus hombres a mercaderes que transitaban por las cercanías. El personaje -al igual que los anteriores y tantos otros- aparece como un verdadero malhechor al frente de un grupo armado, al mismo tiempo que encubría a otros individuos no menos dados al delito y simultáneamente actuaba sin dudarlo en la conflictividad de la época ${ }^{47}$. Así pues, de una u otra forma, aparece involucrado en buen número de hechos violentos al comienzo del reinado de los Reyes Católicos, cuando la inestabilidad -una vez más- era grande en Castilla.

No sería muy difícil encontrar sucesos de morfología muy parecida en contextos diferentes. Sin entrar en el trasfondo de unos acontecimientos que no se deben siempre a las mismas circunstancias, podemos acudir a Galicia, donde salta a la vista la importancia de las fortalezas como plataforma de unos actos realizados por hombres que seguían a miembros de la nobleza regional y que recorriendo el monte sin freno cometían principalmente robos de toda índole, además de secuestros, etcétera ${ }^{48}$; y parecido sería el panorama violento asociado a los parientes mayores vascos, siempre sin olvidar que la pequeña nobleza podía sentir la tentación de recurrir a la depredación como forma de salida de sus costumbres belicosas y/o para completar unos ingresos que no siempre permitían el deseable desahogo ${ }^{49}$. Como he aclarado antes, aunque las causas puedan ser diversas, la praxis de la violencia que surge de los intereses nobiliarios es bastante uniforme y responde en general a las formas propias de la "guerra en migajas" característica de la época. Sin duda, las circunstancias históricas varían considerablemente, pero para la nobleza la violencia era, al fin y al cabo, parte fundamental de su forma de vida y, una de las principales bases sobre las que se apoyaba su proyección pública. Así era tanto en lo concerniente a su prestigio como en relación a la capacidad de maniobra que pudieran desplegar y las posibilidades para consolidar sus redes clientelares.

A tal fin, contaban con comitivas de escuderos y criados, a las que de manera más o menos difusa podían sumarse individuos procedentes de los bajos fondos. La inserción de estos malhechores en el círculo de los poderosos es un fenómeno habitual y muy conocido, y a ellos cabría sumar los escuderos andariegos que aparecen, por ejemplo, en el entorno de los parientes mayores vascos ${ }^{50}$. Pero aunque es indiscutible la contribución de todos estos a la violencia armada de las bandas que se mueven por los campos castellanos, el verdadero núcleo de los grupos armados que rodeaban a los nobles era mucho más estable y estaba formado por criados y escuderos, ya mencionados, acostumbrados a las armas

del caballero de construirse un señorío.

47 Sigo en lo referente a este personaje a J. I. Mendoza Garrido, Delincuencia y represión..., pp. 306 y $320-23$.

48 Sobre esta temática F. Lojo Piñeiro, A violencia na Galicia do século XV, Santiago de Compostela, 1991. Hace años C. Barros tras estudiar la violencia nobiliaria gallega en esta época, acuñó la noción "mentalidad justiciera" que sería "una compleja actitud colectiva que predispone a la acción para hacer observar la justicia infligida, para restablecer el equilibrio del derecho; la mentalidad justiciera de revuelta es hacer justicia mediante la revuelta popular". Ver su libro Mentalidad justiciera de los irmandiños, siglo XV, Madrid, 1990, la cita en la p. 240.

49 Procede citar en este punto la obra de I. Bazán Díaz, Delincuencia y criminalidad en el País Vasco en la transición de la Edad Media a la Moderna, Vitoria, 1995, pp. 442-43.

50 Ibídem, p. 497. La presencia de acotados o perseguidos de la justicia en los bandos que actúan en el País Vasco se menciona en Fernández de Larrea Rojas, "Bandidaje y épica: Ios orígenes históricos del Candar de Sandailia", Anuario del Seminario de Filología Vasca 'Julio de Urquijo', XLII-1 (2008) p. 383. Ver, en general, el volumen colectivo Los señores de la guerra y de la tierra: nuevos textos para el estudio de los Parientes Mayores guipuzcoanos (1265-1548), San Sebastián, 2000. Interesa consultar en el mismo la colección de textos reunidos J. A. LEMA Pueyo, J. A. Fernández de Larrea, E. García Fernández, J. A. Munita Loinaz, J. R. Díaz de Durana. 
y que con la mayor facilidad aparecen inmersos en los más diversos delitos y altercados ${ }^{51}$. Más allá de esto contaban también con el alcance de sus clientelas. De esta forma, actuaban en el territorio siempre mediante grupos no muy grandes que operaban con el apoyo de torres y fortalezas del modo que ha quedado indicado. Es indudable que estos principios generales podrán variar en función de la coyuntura y las circunstancias históricas de cada ámbito del reino, y siempre en función de la categoría de cada uno de los caballeros inmersos en tales aconteceres, pero es lo cierto que nada de todo ello puede considerarse excepcional sino, por el contrario, característico de la época.

En estas condiciones salta a la vista la función que torres y castillos tuvieron en los hechos que acabamos de mostrar, de forma que una conclusión se impone y es que dichas fortificaciones tenían un papel táctico fundamental en las correrías de las bandas ${ }^{52}$, sea como refugio o como plataforma desde la cual desplegar sus acciones. Pero, además, no era raro que muchos alcaides cometieran desde ellas toda clase de abusos, haciendo gala de comportamientos verdaderamente violentos y utilizando, una vez más, pequeños grupos, bien sea para amedrentar o directamente para robar o secuestrar ${ }^{53}$. En algunas ocasiones se nota claramente que son iniciativas destinadas exclusivamente a la obtención de beneficio económico para el propio responsable del castillo y sus hombres, pero con la mayor frecuencia tales actos violentos han de entenderse en el contexto más amplio de los intereses que tenían los mentores nobiliarios de los protagonistas de dichos actos.

\section{PARA TERMINAR...}

En las páginas precedentes nos hemos ido encontrando con la peripecia de una variedad de bandas armadas que actuaron en distintas regiones de la Corona de Castilla, al compás de las cambiantes condiciones de los siglos XIII al XV. En este recorrido si hay algo de todo punto evidente es la inserción de estos grupos violentos en los entramados propios de la sociedad feudal y la consecuente correlación entre la conflictividad propia de las sucesivas coyunturas políticas y la virulencia y número de estos grupos. Así pues, la disputa por el poder en sus diferentes manifestaciones, e incluso el mero ejercicio del mismo, desempeñó un papel decisivo en lo que se refiere a la acción de las bandas que hemos estudiado. Por lo tanto, no cabe contemplar estos comportamientos delictivos en sí mismos independientemente de la evolución política y los intereses de los estratos sociales dominantes.

Si con frecuencia se ha querido distinguir diferentes tipos de bandidaje -sea económico, político, social, etcétera-, creo que los aspectos que sucesivamente se han analizado

51 Ó. LÓPEZ GÓMEZ, La sociedad amenazada..., p. 252. Este autor ha prestado atención a los grupos armados que estamos estudiando, poniendo muy bien de relieve cómo tales grupos reflejan el poderío del noble, pp. 253 y ss. En cuanto a delitos protagonizados por escuderos, citemos simplemente la actuación hermandina contra los de Pedro de Ayala que había tomado diversas cosas en Retuerta de Bullaque cuando el conde estaba en contra de la ciudad de Toledo, Archivo General de Simancas, Registro General del Sello, 1477-III, folio 455.

52 Son varias las ocasiones en que se elevaron peticiones al rey sobre este tema y el argumento ha sido recogido por los historiadores con bastante frecuencia y desde hace mucho tiempo. Puede verse, por ejemplo, en C. López Alonso, La pobreza en la España medieval, Madrid, 1986, p. 217, que indica que los castillos estaban estrechamente vinculados a la actividad depredadora de la nobleza y sirvieron como refugio de malhechores. El estudio de un caso monográfico en I. Bazán Díaz, "El refugio de la delincuencia señorial. Torres y casas fuertes en el País Vasco: el ejemplo de la torre de Berna", Sancho el Sabio, 8, 1998, pp. 23-50. En fin, es éste un tema realmente tópico, pero no por ello menos cierto.

53 Los casos son tan abundantes que podríamos prolongar esta cita interminablemente. Cuenta algunos en el siglo XV -incluyendo secuestros para cobrar rescate. Ó. LÓPEZ GÓMEZ, La sociedad amenazada..., pp. 325-27. 
en el presente artículo vienen a mostrar con claridad que tales tipologías se desvanecen, porque los factores de diversa índole que intervienen en el desarrollo de las bandas se entremezclan de manera realmente compleja. Por lo tanto, en las circunstancias históricas en que se desenvuelven estos grupos entre los siglos $\mathrm{XIII}$ y $\mathrm{XV}$, tales tipos devienen un verdadero corsé que sólo supone rigidez y poco o nada aporta, del mismo modo que definir cada uno de esos tipos constituye empeño casi imposible.

En fin, queda claro a la vista de lo expuesto que en la época que nos interesa el poder, la fuerza y el miedo tienen mucho que ver ${ }^{54}$. La violencia era sin duda imprescindible para el verdadero grupo dominante que era la nobleza. Les resultaba útil y formaba parte de su misma naturaleza, pero debía ejercerse de una manera concreta -que en su momento hemos puesto de manifiesto- y es ahí donde entran las bandas y su forma de actuar, porque se adecuaba muy bien a las posibilidades y medios existentes. De modo que en los campos despoblados la acción armada de los poderosos se realizaba las más de las veces a través de bandas para las cuales el botín era absolutamente fundamental desde muchos puntos de vista. Debemos aceptar pues que la estructura política y social de la época favorecía claramente la violencia. Claro que a los ojos de todos, tanto aldeanos como ciudadanos y sus concejos, estos hechos constituían abusos manifiestamente contrarios a la justicia, verdaderos delitos, y por eso reclamaban, cuando podían, pretendiendo la sanción legal que corresponde al acto delictivo y, en su caso, la reparación de lo robado o destruido.

54 "El poder, la fuerza, la autoridad y la violencia medievales eran términos sinónimos" dice J. A. Solórzano Telechea, "Violencia y conflictividad política en el siglo XV: el delito al servicio de la élite en las cuatro villas de la costa de la mar", Anuario de Estudios Medievales, 35/1 (2005) p. 160. 